$\xi_{p}$

\title{
Perforated Weir for Effective Operation - A Study
}

\author{
Gowthami Gunjalli ${ }^{1}$, Aishwarya $S^{2}$, Muthu $D^{3}$, Venkata Subramaniam $C^{4}$, Ramakrishnan ${ }^{5}$ \\ ${ }^{1,2}$ Post graduate student, ${ }^{3}$ Assistant Professor, ${ }^{4}$ Associate Professor, ${ }^{5}$ Senior Assistant \\ 1,2,3,4,5 School of Civil Engineering, SASTRA Deemed to be University, Thanjavur, TamilNadu, India \\ *Corresponding Author E-mail: ${ }^{1}$ gauthami.g97@gmail.com, ${ }^{2}$ aishwarysm@gmail.com, \\ ${ }^{3}$ dmuthu@civil.sastra.edu, ${ }^{4}$ cv@civil.sastra.edu, ${ }^{5}$ ramakrishnan@civil.sastra.edu
}

\begin{abstract}
The excess water during monsoon season in the river is retained using low dams and it overflows through weirs. Maintaining the water depth at the required level and increasing the discharge from the weir are the current problems facing now a days. To overcome these problems, a novel sharp crested perforated weir has been developed in this work with different shapes of perforations viz. circle, rectangle, square and triangle having same area of perforation. A total of 24 models were made with single, double, triple opening for each shape, under two different sets of area of openings. The models were examined in a hydraulic tilting flume by keeping the discharge as constant. The variation in head obtained from these perforated weirs for different shapes were compared with a control weir which is a sharp crested rectangular weir. The expected theoretical discharge from these perforated weirs is compared with the actual discharge obtained. The values of coefficient of discharge for different perforated weirs were obtained by minimizing the error and the effective perforated weir is arrived by analyzing the values. This solution can be applied in solving practical problems.
\end{abstract}

Keywords: Perforated weir, Coefficient of discharge, Head of water.

\section{Introduction}

A control over the water level and regulation of discharge are essential for the purpose of irrigation, water conservation, flood alleviation and inland navigation. A wide variety of hydraulic structures are available to satisfy the specific need; It ranges from the weirs or sluices encountered in small water courses to the overflow spillways of large dams. In the present scenario, weirs are the most commonly used control structures in practice (Kumar S et al., 2012). A weir is a regular obstruction in an open stream over which the flow takes place. They are broadly classified on the basis of shape, nature of discharge, width of crest and the nature of crest (Emad Abdul Gabbar et al., 2011).

Sharp crested weirs are the commonly used weir, limited its application to laboratories, small artificial channels and streams due to slender structure ( Bagheri S et al., 2010; Johnson M.C et al., 1999). This makes it too vulnerable to handle the debris laden flood discharges that occur periodically in most rivers and under continuous operating conditions becomes rounded crest which effects the calibration.

Overcoming these practical limitations special types of weirs are developed by increasing the crest length (Anderson R.M et al., 2012). The need for an optimal design and economic consideration makes it difficult for the engineers to adopt in practice.

Maintaining the water depth at a required level and increasing the discharge from the weirs is the two flood problems faced these days. In the past, several types of weirs have been developed to increase the discharge from the weir.
In most of the cases the length of the weir has been increased keeping its width constant in order to increase the discharge (Khode B.V et al., 2010). Other major change is that the angle between the weir crest and the base of the channel has been change from right angle .These types of weirs are known as non linear weirs. In places, where the length of channel is limited, these special types are not of much use. Moreover, the complexity in design and execution in such type of weirs would make it much more expensive.

Perforated weir is a new type of non linear weir which is similar to that of sharp crested rectangular weir with an opening in it. It aims at maintaining the head at required level and increase the discharge by not increasing the length compared to its width. The other major change is that the angle between the weir crest and base of the channel has been kept at right angle. The openings are made with different shapes and the performance is analyzed in the project. Since the construction is simple and economical in this case, the establishment of the same in practice would be beneficial.

The main aim of this project is to study the performance of perforated sharp crested weir with different sizes and shapes of perforation.

\section{Factors Affecting the Flow Characteristics}

\subsection{Velocity of Approach}

The water approaching the weir has got some velocity known as velocity of approach which is assumed to be uniform over the entire weir.

$\mathrm{V}=\frac{Q}{A}$ 
Where, V - Velocity of approach

$\mathrm{Q}$ - Discharge over the weir

A - Cross sectional area of the channel on upstream side of the weir When the water flows over the weir, the nappe creates a space beneath the weir which traps the air forming a negative pressure beneath the nappe. It results in more discharge than the normal discharge. In order to keep the atmospheric pressure in space below, the nappe holes are provided called as Ventilation of a weir.

\section{Experimental Apparatus}

Tests are conducted in a rectangular flume of length $3 \mathrm{~m}$, width $0.15 \mathrm{~m}$ and depth $0.3 \mathrm{~m}$. Two sets of wooden models of length 0.15 $\mathrm{m}$, height $0.1 \mathrm{~m}$, having different area of perforation were prepared. A total of 24 models were developed with different shapes of perforations such as circle, rectangle, square and triangle.

They were placed in hydraulic tilting flume and were sealed with wood sealant. A control weir (Sharp crested rectangular weir) was placed in the arrangement and water head for different flow rates were obtained.

For control weir

$\mathrm{Q}=0.000235\left(\left(\mathrm{~h}_{1}-\mathrm{h}_{2}\right) \times 12.6\right)^{1 / 2} \mathrm{~m}^{3} / \mathrm{s}$

$\mathrm{Q}_{\text {sharp crested weir }}=2 / 3 * \mathrm{C}_{\mathrm{d}} * \mathrm{~L} *(2 \mathrm{~g})^{1 / 2} * \mathrm{H}^{3 / 2} \mathrm{~m}^{3} / \mathrm{s}$

Then perforated weirs with single, double, triple opening for each shape were placed and the water head were obtained for the same values of flow rates that were kept for control section.

The discharge through these perforated weirs was considered to be a combination of discharges through the opening (which is assumed to be an orifice) and over the sharp crested weir.

Perforated weirs

$\mathrm{Q}$ orifice $=\mathrm{A} * \mathrm{C}_{\mathrm{d}} *(2 \mathrm{gh})^{1 / 2} \mathrm{~m}^{3} / \mathrm{s}$

$\mathrm{Q}$ sharp crested weir $=2 / 3 * \mathrm{C}_{\mathrm{d}} * \mathrm{~L} *(2 \mathrm{~g})^{1 / 2} * \mathrm{H}^{3 / 2} \mathrm{~m}^{3} / \mathrm{s}$

Table 1: Dimensions of Different Shapes

\begin{tabular}{|c|c|c|}
\hline Shape & Dimension & $\operatorname{Area}\left(\mathrm{m}^{2}\right)$ \\
\hline Circle & 0.0254 & 0.000506707 \\
\hline Circle & 0.01905 & 0.000285138 \\
\hline Triangle & 0.0342 & 0.000506707 \\
\hline Triangle & 0.0256 & 0.000285138 \\
\hline Square & 0.0225 & 0.000506707 \\
\hline Square & 0.0168 & 0.000285138 \\
\hline Rectangle & $\begin{array}{l}0.03 \\
0.0168\end{array}$ & 0.000506707 \\
\hline Rectangle & $\begin{array}{l}0.0285 \\
0.01\end{array}$ & 0.000285138 \\
\hline
\end{tabular}

The coefficient of discharge values of overflow over the weir and orifice are kept as $\mathrm{C}_{\mathrm{d} 1}$ and $\mathrm{C}_{\mathrm{d} 2}$ respectively. For control weir it is $\mathrm{C}_{\mathrm{d}}$.

Table 2: $\mathrm{C}_{\mathrm{D}}$ Values for Control Section

\begin{tabular}{|l|l|l|l|l|}
\hline $\mathrm{h}_{1}(\mathrm{~m})$ & $\mathrm{h}_{2}(\mathrm{~m})$ & $\mathrm{y}(\mathrm{m})$ & Discharge $\left(\mathrm{m}^{3} / \mathrm{s}\right)$ & $\mathrm{C}_{\mathrm{d}}$ \\
\hline 0.252 & 0.14 & 0.236 & 0.00279 & 0.8028 \\
\hline 0.26 & 0.133 & 0.2365 & 0.00297 & 0.8339 \\
\hline 0.27 & 0.123 & 0.24 & 0.00319 & 0.7958 \\
\hline 0.28 & 0.111 & 0.241 & 0.00342 & 0.8247 \\
\hline 0.301 & 0.0915 & 0.248 & 0.00381 & 0.7375 \\
\hline 0.331 & 0.062 & 0.2525 & 0.00432 & 0.7370 \\
\hline 0.357 & 0.034 & 0.257 & 0.00474 & 0.7192 \\
\hline
\end{tabular}

The $C_{d}$ value was substituted from $0.44-0.60$ for orifice $\left(C_{d 1}\right)$ and for overflow $\left(\mathrm{C}_{\mathrm{d} 2}\right)$ 0.70-0.80 to the discharge equations obtained for perforated weirs. The difference between the expected theoretical discharge and the actual discharge obtained by substituting these $C_{d}$ values were found. The $C_{d}$ values that results the lowest error were taken as the $C_{d}$ values for that weir.

Min Error $=\sum\left(\mathrm{Q}_{\text {observed }}-\mathrm{Q}_{\text {theoretical }}\right)$

The average percentage decrease in head for single, double and triple perforations of each shape were found. The shape that produced the maximum average percentage decrease was considered as the most efficient for that particular type of perforation.

\section{Results and Discussions}

Based on the average values of percentage decrease in head, the most efficient shape, for each type of perforation is tabulated.

Table 3: Most Efficient Shape For Each Type Of Perforation

\begin{tabular}{|l|l|l|l|}
\hline $\begin{array}{l}\text { Area of opening } \\
\left(\mathrm{m}^{2}\right)\end{array}$ & $\begin{array}{l}\text { Single } \\
\text { perforation }\end{array}$ & $\begin{array}{l}\text { Double } \\
\text { perforation }\end{array}$ & $\begin{array}{l}\text { Triple } \\
\text { perforation }\end{array}$ \\
\hline 0.000506707 & Square & Triangle & Square \\
\hline 0.000285138 & Square & Circle & Triangle \\
\hline
\end{tabular}

When the stimulation for finding the optimum coefficient of discharge was performed by minimizing the error, majority of the weirs under consideration seemed to follow the usual trend in the coefficient of discharge values, namely $\mathrm{C}_{\mathrm{d} 1}=0.8$ and $\mathrm{C}_{\mathrm{d} 2}=0.6$.

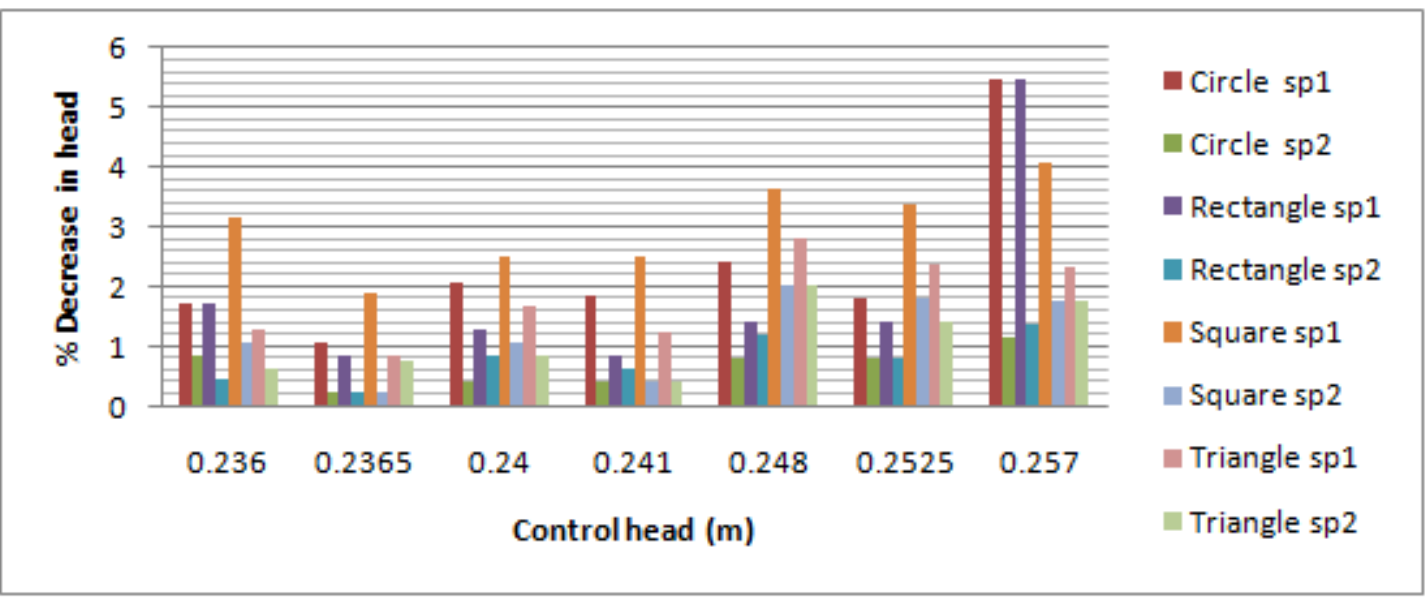

Fig. 1: Comparison between Control Head and Percentage Decrease in Head for Single Perforation 


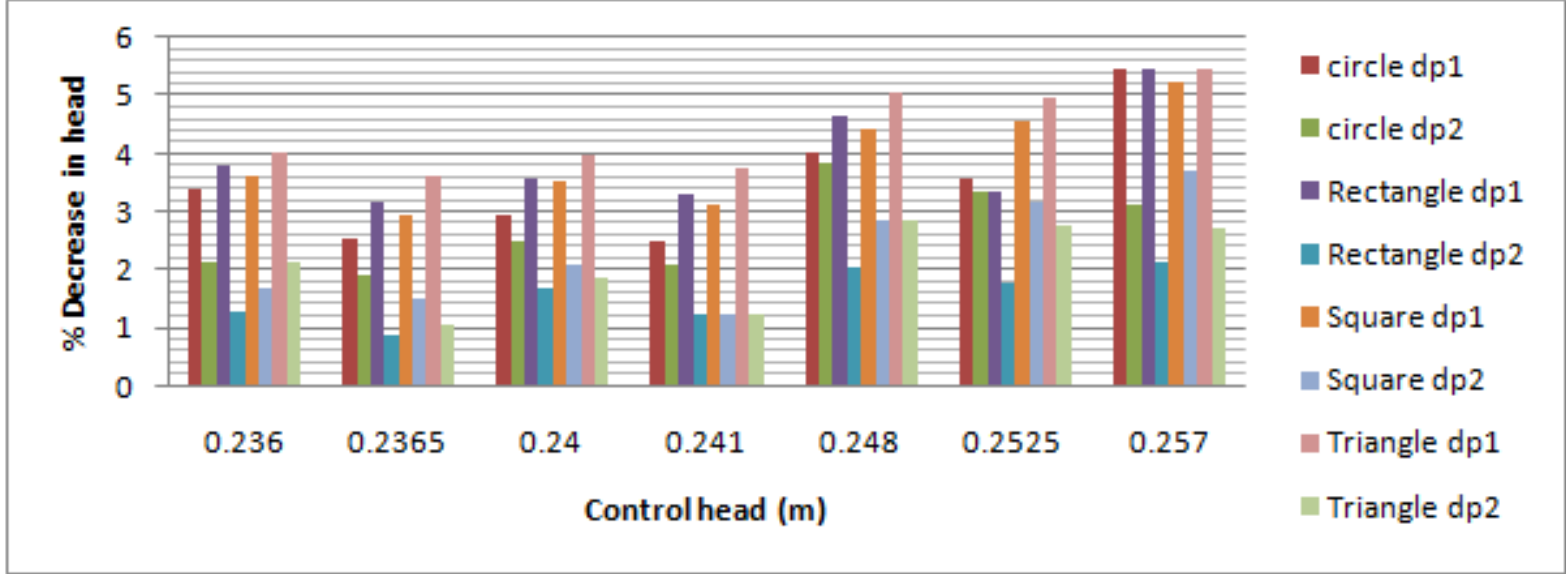

Fig. 2: Comparison between Control Head and Percentage Decrease in Head for Double Perforation

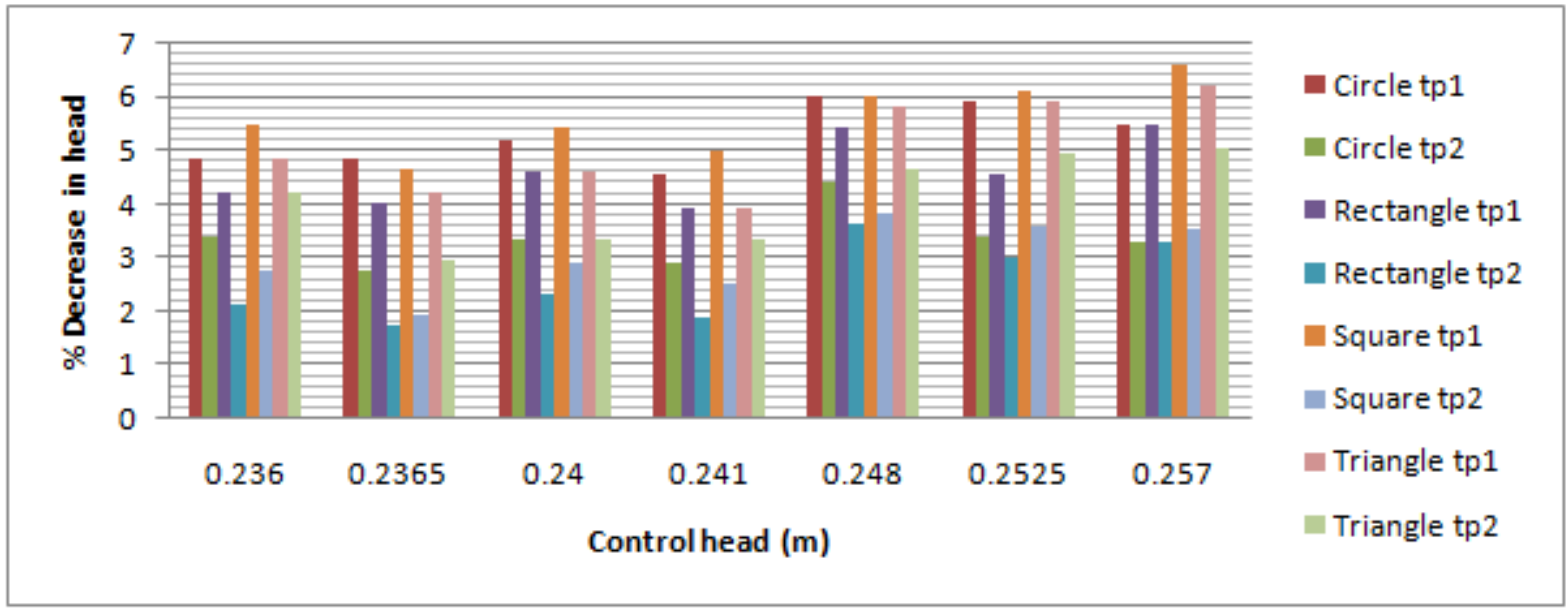

Fig. 3: Comparison between Control Head and Percentage Decrease in Head for Triple Perforation

Based on the analysis of percentage decrease in head, square shaped perforation was found to exhibit maximum performance as it had maximum mean percentage decrease in head in case of single and triple perforation. Geometrical symmetry and uniform crosssectional area of opening from bottom to top might be a reason for its superior performance.

Moreover, there are more losses in rectangular and triangular perforations as it has a greater perimeter for the same area of opening compared to the square shaped perforation and surface of contact is more.

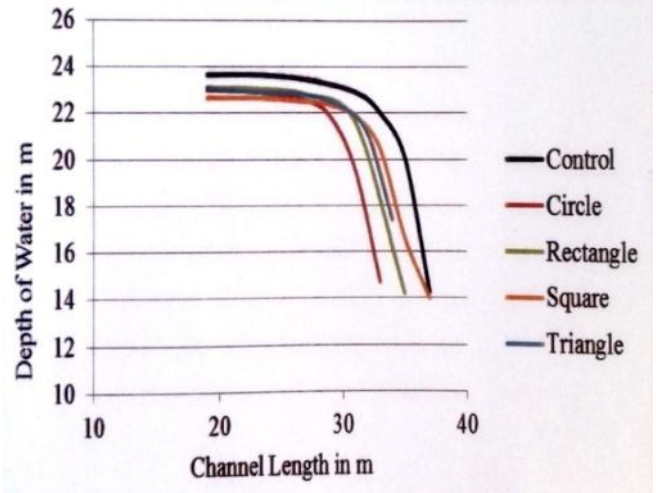

a) Lower Profile - Single Perforation with Area $0.000506707 \mathrm{~m}^{2}$

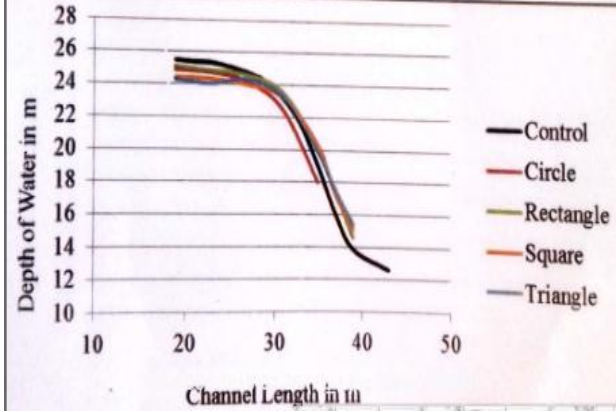

b) Higher Profile - Single Perforation with Area $0.000506707 \mathrm{~m}^{2}$

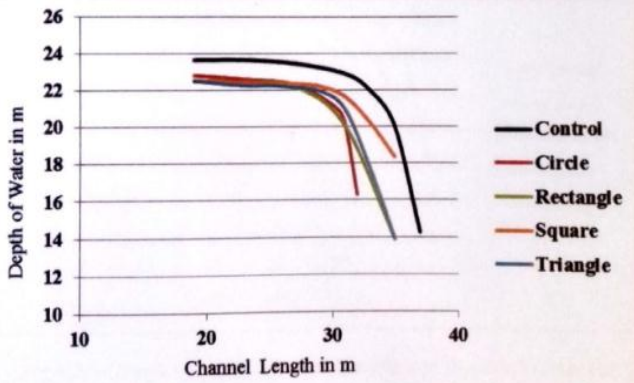

c) Lower Profile - Double Perforation with Area $0.000506707 \mathrm{~m}^{2}$ 


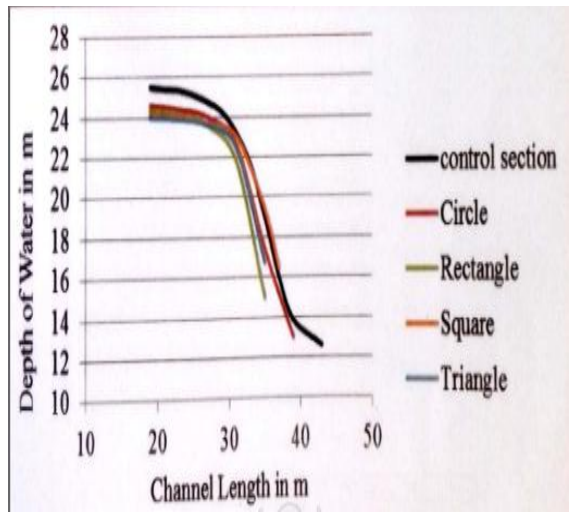

d) Higher Profile - Double Perforation with Area $0.000506707 \mathrm{~m}^{2}$

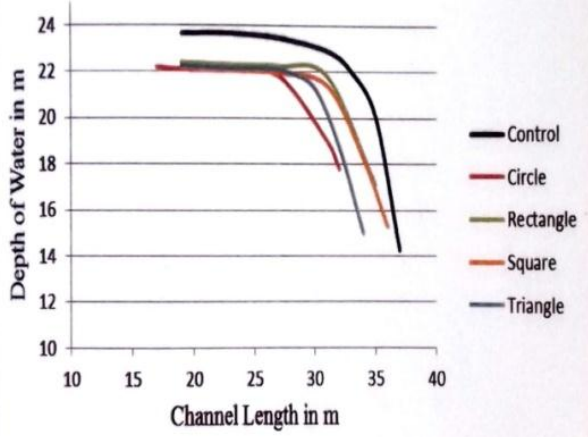

e) Lower Profile - Triple Perforation with Area $0.000506707 \mathrm{~m}^{2}$

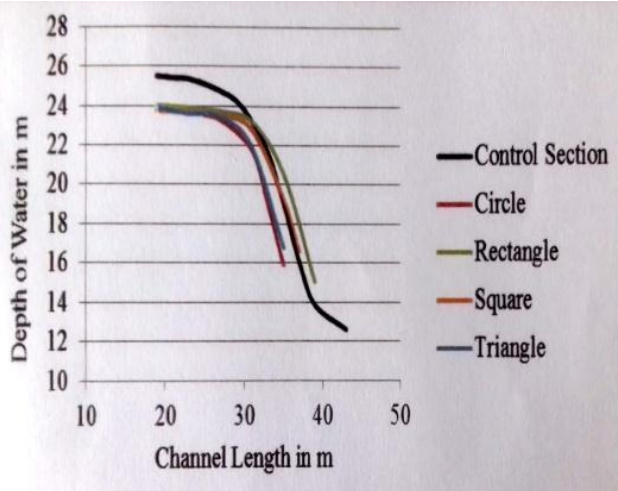

f) Higher Profile - Triple Perforation with Area $0.000506707 \mathrm{~m}^{2}$

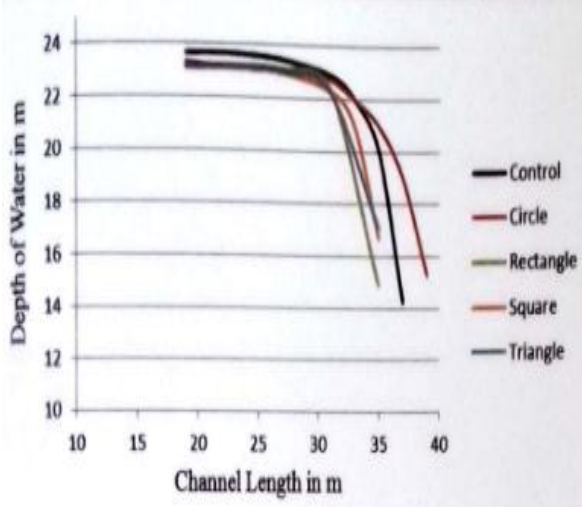

g) Lower Profile - Single Perforation with Area $0.000285138 \mathrm{~m}^{2}$

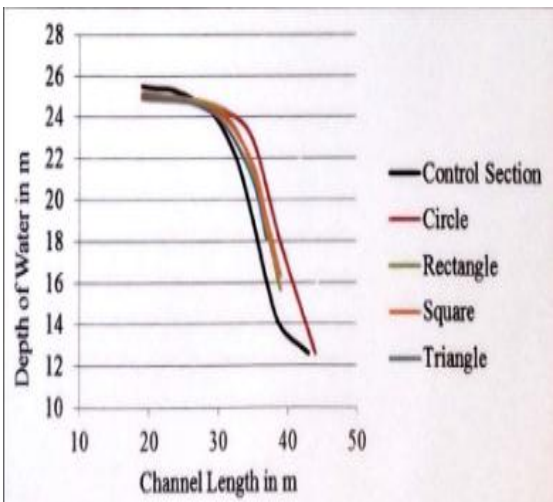

h) Higher Profile - Single Perforation with Area $0.000285138 \mathrm{~m}^{2}$

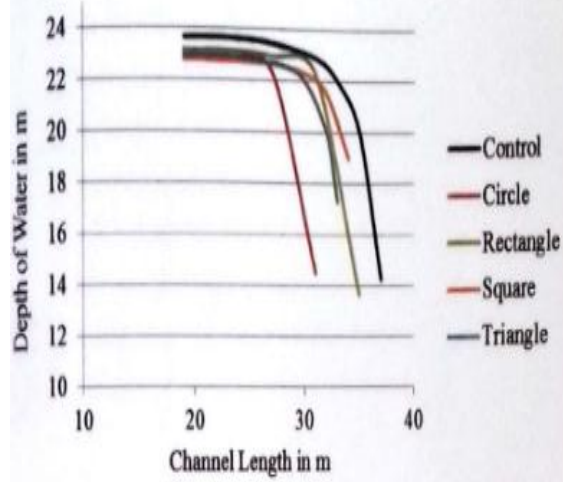

i) Lower Profile - Double Perforation with Area $0.000285138 \mathrm{~m}^{2}$

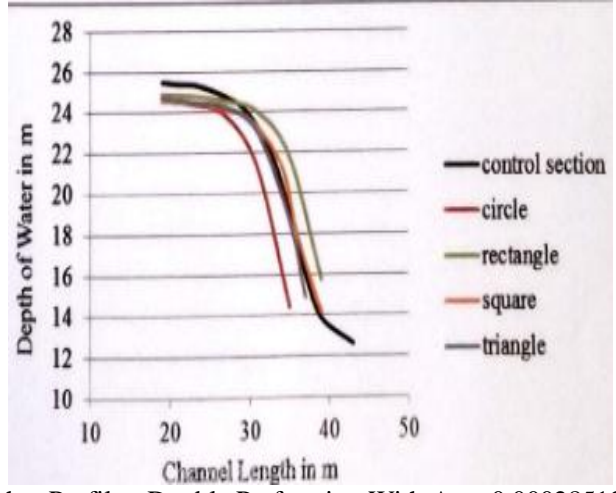

j) Higher Profile - Double Perforation With Area $0.000285138 \mathrm{~m}^{2}$

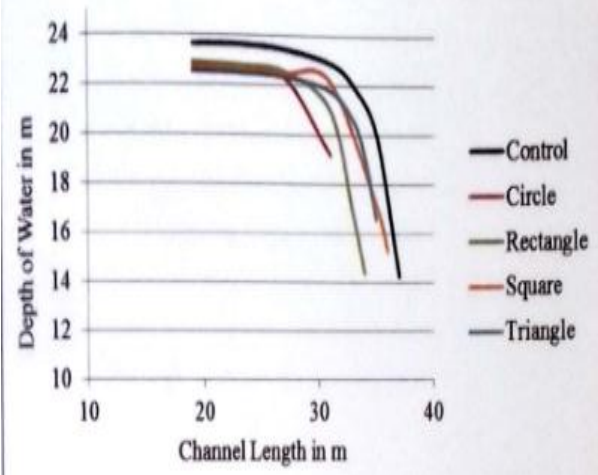

k) Lower Profile - Triple Perforation With Area $0.000285138 \mathrm{~m}^{2}$ 


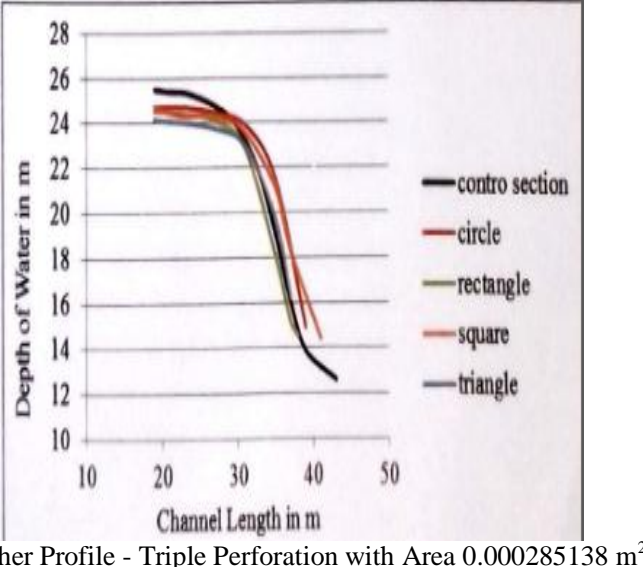

Higher Profile - Triple Perforation with Area 0.000285138 m
Fig. 4: Graph between Channel Length and Depth of Water

Based on the study of profiles at minimum and maximum flow rates, At Lower profile: As an effect of perforation there is a decrease in head in perforated weir, which leads to water jet falling at a shorter distance, when compared to the fall in a control weir.

At Higher profile: When the water flows at a high rate, though there is slight decrease in head due to perforation, the quantity of water jet coming from these perforations is very less and hence much variation between profiles of control and perforated weir were not noted.

\section{Conclusions}

For most of the developed perforated weirs the coefficient of discharge for orifice and overflow was found to be 0.6 and 0.8 . Based on the analysis of percentage decrease in head, square shaped perforation was found to be the most effective. At lower flow rates due to perforations the water falls at a shorter distance when compared to the normal sharp crested weirs. At a higher flow rates this effect is less pronounced due to fact that the quantity of water coming from these perforations are less and hence the water falls at a greater distances as that of control weir. This can be practically adopted for solving the major flood problems as stated.

\section{Abbreviation}

Q - Discharge from the weir

h1, h2 - Head of water

$\mathrm{Cd}$ - Coefficient of discharge for control weir

$\mathrm{L}$ - Length of the weir

g - Acceleration due to gravity

$\mathrm{H}$ - Head of overflow water

A - Area of perforation

$\mathrm{h}$ - Head of water from the orifice

Cd1 - Coefficient of discharge for overflow

$\mathrm{Cd} 2$ - Coefficient of discharge for orifice

sp1 - Single perforation of area $0.000506707 \mathrm{~m} 2$

dp1 - Double perforation of area $0.000506707 \mathrm{~m} 2$

tp1 - Triple perforation of area $0.000506707 \mathrm{~m} 2$

sp2 - Single perforation of area $0.00028538 \mathrm{~m} 2$

dp2 - Double perforation of area $0.00028538 \mathrm{~m} 2$

tp2 - triple perforation of area $0.00028538 \mathrm{~m} 2$

\section{Reference}

[1] Kumar S and Ahmad Z, "Discharge Characteristics of Sharp Crested Weir of Curved plan-form", Research Journal of Engineering Sciences, 2012, Vol.1(4), pp. 16-20.

[2] Emad Abdul Gabbar and Adman Abdul Wahab, "Overflow Characteristics of Cylindrical Shape Crest Weirs Over Horizontal Bed", Tikrit Journal of Engineering Sciences, 2011, vol. 18(4), pp. 2939.

[3] Bagheri S, "Flow over rectangular sharp- crested weirs", Irrigation Science, 2010, Vol. 28, pp. 173-179.

[4] Johnson M.C, "Discharge co-efficient analysis for flat-topped and sharp-crested weirs", Irrigation Science, 1999, Vol. 19, pp. 133-137.

[5] Anderson R.M and Tullis B.P, "Piano Key weir hydraulics and labyrinth weir comparison", Journal of Irrigation and Drainage Engineering, Vol. 139(3), pp. 246-253.

[6] Khode B.V, "Evaluation and analysis of crest coefficient for labyrinth weir", World Applied Sciences Journal, 2010, Vol. 11(7), pp. 835839 